\title{
Goldenhar Syndrome with Occipital Meningoencephalocele: A Rare Case
}

\author{
Mubashshir Ali*, Ashish Chugh, Deepak M. Ranade \\ Department of Neurosurgery, Dr. D. Y. Patil Medical College, Pune, India \\ Email: ^luckin2010@gmail.com
}

How to cite this paper: Ali, M., Chugh, A. and Ranade, D.M. (2019) Goldenhar Syndrome with Occipital Meningoencephalocele: A Rare Case. Open Journal of Modern Neurosurgery, 9, 17-22. https://doi.org/10.4236/ojmn.2019.91003

Received: October 11, 2018

Accepted: December 10, 2018

Published: December 13, 2018

Copyright $\odot 2019$ by authors and Scientific Research Publishing Inc. This work is licensed under the Creative Commons Attribution International License (CC BY 4.0).

http://creativecommons.org/licenses/by/4.0/

\section{(c) (i) Open Access}

\begin{abstract}
A 7-year-old male patient reported in our neurosurgery OPD with chief complaints of swelling in occipital region. The swelling was gradually increasing in size as per history given by patient's attendant. Antenatal and birth history was uneventful. Developmental milestones were normal. Ear examination showed left sided pre auricular tag. Hearing was normal. Eye examination showed right eye limbal dermoid. Limbs examination showed syndactyly of 5th finger. Cardiovascular, respiratory and oral examination was normal. His height and weight were within normal limit. Chest X-ray was normal. Skeletal survey did not show any vertebral deformities. The karyotype was normal. The MRI brain showed a defect of size $1.3 \mathrm{~cm}$ in the occipital region through which cerebellum was seen herniating. The mass was surrounded by hypodense collection with multiple thickened septae within suggestive of CSF collection with thickened meninges. Patient underwent surgery and cystic portion was removed, with preservation of the occipital and cerebellar parenchyma and closure of defect was done. Patient responded well that there were no post operative complications and child was discharged on the 10th postoperative day. Hence, based on clinical and radiographic findings, a diagnosis of Goldenhar syndrome was made.
\end{abstract}

\section{Keywords}

Goldenhar Syndrome, Limbic Nodule

\section{Introduction}

Mauric Goldenhar who was a Swiss ophthalmologist in 1952 first described about Goldenhar which is a rare congenital malformation caused due to defective development of first \& second brachial arches. GS is a rare congenital malformation occurring due to defective development of first and second branchial 
arches. Gorlin et al. in 1963 [1] coined the term oculoauriculo vertebral dysplasia. It involves face, eyes, ears and vertebrae with varying severity [2].

In this disease, right side is more habitually affected amongst which $85 \%$ abnormalities are unilateral and only in $10 \%-23 \%$ of cases, it is bilateral [3]. It has been reported that incidence of Goldenhar syndrome fluctuates from 1:3500 to 1:5600 of live births. 1:1000 children suffer with congenital deafness in which male to female ratio is 3:2 [4]. The etiology of this disease is not fully understood and it is seen as sporadic diseases. Interaction of many genes possibly in combination with environmental factors causes malfactorial inheritance being suggested by some researchers [5].

We reported a case of this rare syndrome with occipital meningoencephalocele in 7-year-old male child. Instead of slight facial and skeletal involvement, some patents with Goldenhar syndrome are also suffering from prominent central nervous system involvement.

\section{Case Report}

A 7-year-old male patient reported in our neurosurgery OPD with chief complaints of swelling in occipital region. The swelling was gradually increasing in size as per history given by patient's attendant. Antenatal and birth history was uneventful. Developmental milestones were normal. Ear examination showed left sided pre auricular tag (Figure 1). Hearing was normal. Eye examination showed right eye limbal dermoid (Figure 2). Limbs examination showed syndactyly of $5^{\text {th }}$ finger (Figure 3). Cardiovascular, respiratory and oral examination was normal. His height and weight were within normal limit. Chest X-ray was normal. Skeletal survey did not show any vertebral deformities. The karyotype was normal. The MRI brain of our patient revealed a defect of size $1.3 \mathrm{~cm}$ in the occipital region. Cerebellum was seen herniating through this defect. The mass was encovered hypodense collection and multiple thickened septae that is suggestive of CSF collection and thickened meninges (Figure 4).

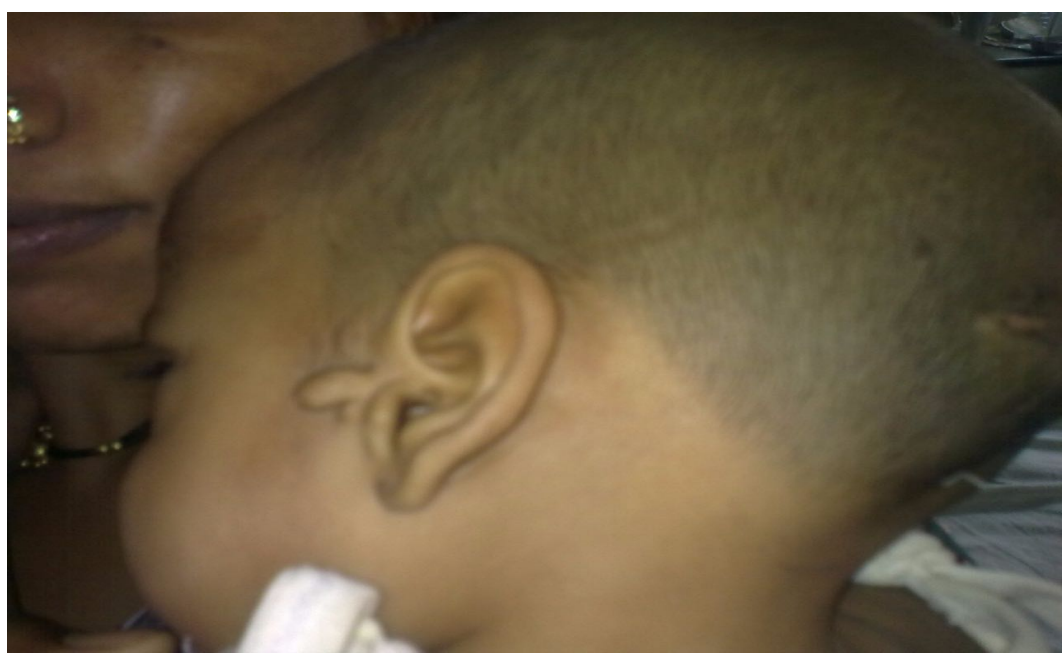

Figure 1. Auricular Tag. 


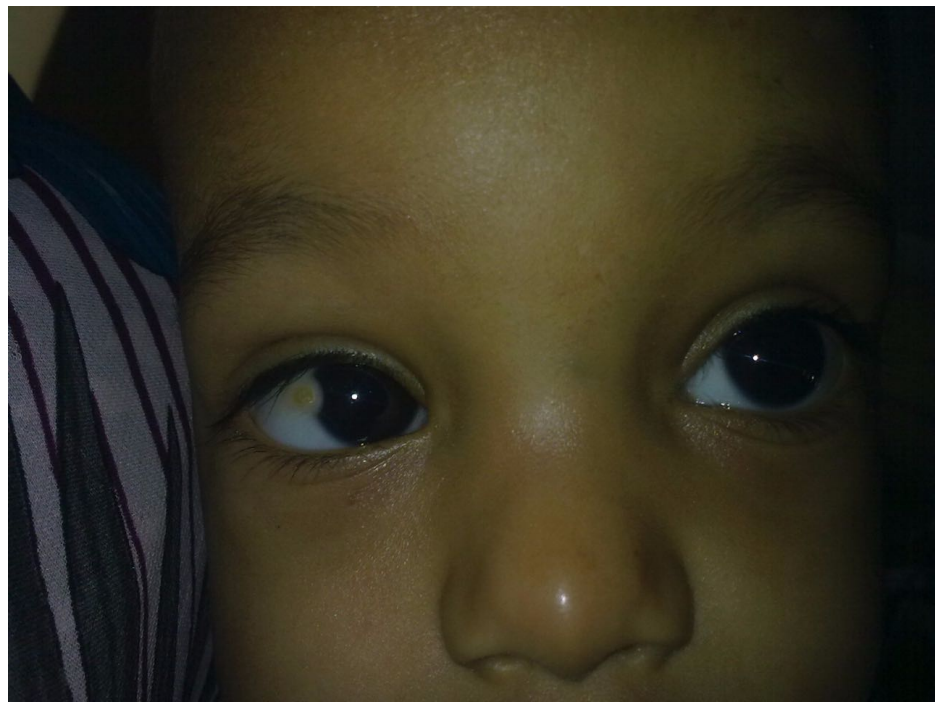

Figure 2. Eye Limbal Dermoid.

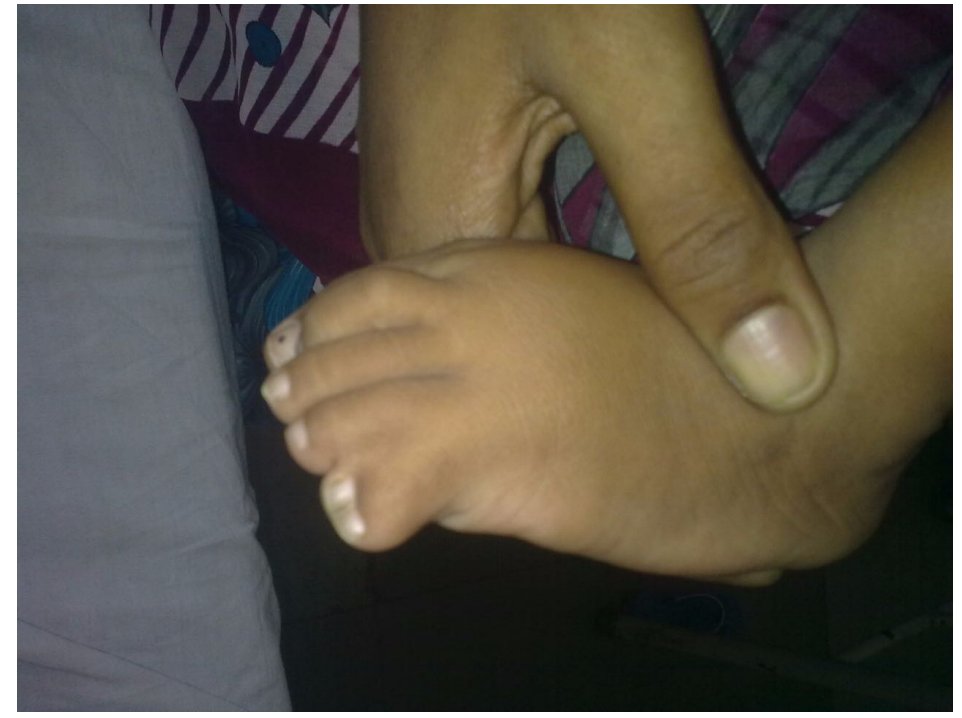

Figure 3. Syn-dactyly.

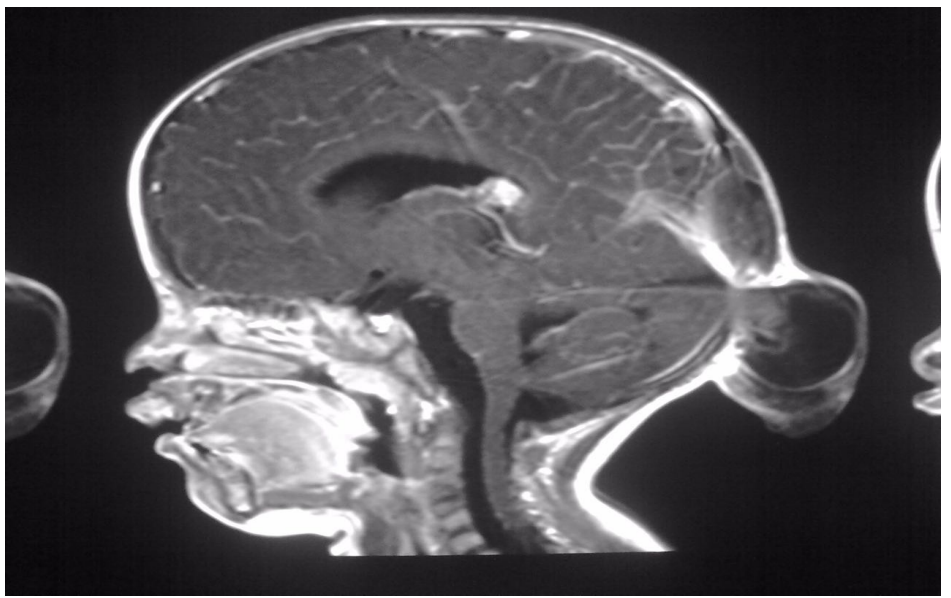

Figure 4. Thickened Meninges. 
Patient underwent surgery and cystic portion was removed, with preservation of the occipital and cerebellar parenchyma and closure of defect was done. Patient responded well there were no post operative complications and child was discharged on $10^{\text {th }}$ postoperative day. Hence based on clinical and radiographic findings, a diagnosis of Goldenhar syndrome was made.

\section{Discussion}

Maurice Goldenhar is classically described as Goldenhar syndrome. Goldenhar syndrome embodies accessory tragic, mandibular hypoplasia and ocular dermoids [6]. Craniofacial features are highly predictable in this syndrome although it circumscribes a range of other features. Goldenhar recognized for the first \& second brachial arches association of epibulbar dermoids, preauricular fistula, abnormalities of skin appendages and ocular malformations as a specific entity [7]. The triad of Goldenhar syndrome is pretragal fistulae, epibulbar dermoids and accessory auricular appendages. If vertebral anomalies are present in addition of this triad, then the diagnosis is further corroborated. If additional symptoms are present, then diagnosis becomes more difficult. In Goldenhar syndrome, we find frequently cranial anomalies polydactyly and hydrocephalus. Occasionally, occipital encephalocele has also been reported. Defective posterior arch of the C-1 vertebral body and cranium bifidum in occipital region has been detected in an autopsy case Goldenhar's syndrome with encephalocele [8].

The diagnosis is further substantiated if vertebral anomalies are present in addition to the triad. The diagnosis becomes more difficult if additional symptoms are present.

Goldenhar syndrome has been seen in association with cranial anomalies. Kumar et al. reported polydactyly and hydrocephalus as rare associations with Goldenhar syndrome [9]. However, occipital encephalocele has been rarely reported. Aleksic et al. observed encephalocele consists of cranium bifidum in the occipital region and imperfect posterior arch of the C-1 vertebral body after an autopsy case of Goldenhar syndrome [8].

Due to delay in growth and development of affected areas, the effect of Goldenhar syndrome becomes more prominent with growth of child.

Patient was suffering from preauricular tag, epibulbar dermoid, syndactyle and occipital meningoencephalocele in our case diagnosis in favor of Goldenhar syndrome. Our patient responded well after being operated for meningoencephalocele. The occulo-vertebral spectrum which is one of the skeletal anomalies was observed. In our case, the occipital meningoencephalocele is caused by dysraphism in occipital bone. Goldenhar syndrome is still being treated hypothetically. It requires multidisciplinary approach. Radiological and laboratory tests validate clinical diagnosis of Goldenhar syndrome.

Presence of preauricular tags along with facial asymmetry mandible/maxilla hypoplasia and epibulbar dermoid is mandatory for diagnosis as suggested by most authors. Identification and management of associated anomalies in Gol- 
denhar syndrome plays chief role in through investigation and proper examination.

Due to delay in growth and development of affected areas of child, consequences of Goldenhar Syndrome are more obvious as the child grows. In our case patient had preauricular tag, epibulbar dermoid, syndactyle and occipital meningoencephalocele were present. These findings were in favor of Goldanhar syndrome. Our patient has been operated for occipital meningencephalocele and responded well. In this case, the possible dysraphism of occipital bone because of meningoencephalocele, which can be the skeletal anomalies seen in the ocluoauriculovertebral spectrum.

Goldenhar syndrome requires integrative approaches as its treatment is conjectural.

The diagnosis of GS is mainly clinical which can be supported by radiological and laboratory tests. Most authors consider that the presence of preauricular tags along with facial asymmetry, mandible/maxilla hypoplasia, and epibulbar dermoid is necessary for diagnosis. Proper examination and thorough investigations play an important role in identifying and management of associated anomalies in Goldenhar syndrome.

\section{Conflicts of Interest}

The authors declare no conflicts of interest regarding the publication of this paper.

\section{References}

[1] Gorlin, R.J., Jue, K.L., Jacobsen, U. and Goldschmidt, E. (1963) Oculoauriculovertebral Dysplasia. The Journal of Pediatrics, 63, 991-999.

https://doi.org/10.1016/S0022-3476(63)80233-4

[2] Berker, N., Acaroğlu, G. and Soykan, E. (2004) Goldenhar's Syndrome (Oculo-Auriculo-Vertebral Dysplasia) with Congenital Facial Nerve Palsy. Yonsei Medical Journal, 45, 157-160. https://doi.org/10.3349/ymj.2004.45.1.157

[3] Bielicka, B., Necka, A. and Andrych, M. (2006) Interdisciplinary Treatment of Patients with Goldenhar Syndrome-Clinical Reports. Dental and Medical Problems, 43, 458-462.

[4] Tuna, E.B., Orino, D., Ogawa, K., Yildirim, M., Seymen, F., Gencay, K., et al. (2011) Craniofacial and Dental Characteristics of Goldenhar Syndrome: A Report of Two Cases. Journal of Oral Science, 53, 121-124. https://doi.org/10.2334/josnusd.53.121

[5] Kulkarni, V., Shah, M.D. and Parikh, A. (1985) Goldenhar Syndrome (A Case Report). Journal of Postgraduate Medicine, 31, 177-179.

[6] Vinay, C., Reddy, R.S., Uloopi, K.S., Madhuri, V. and Sekhar, R.C. (2009) Chandra Craniofacial Features in Goldenhar Syndrome. Journal of Indian Society of Pedodontics and Preventive Dentistry, 27, 121-124. https://doi.org/10.4103/0970-4388.55339

[7] Goldenhar, M. (1952) Associated Malformations of Eye and Ear, Particularly Dermoid Syndrome Epibulbar-Appendices, Congenital Auricular Fistulas and Its Relations with Manibulofacial Dysostosis. Journal of Human Genetics, 1, 243-282.

[8] Aleksic, S., Budzilovich, G., Greco, M.A., McCarthy, J., Reuben, R., Margolis, S., 
Epstein, F., Feigin, I. and Pearson, J. (1984) Intracranial Lipomas, Hydrocephalus and Other CNS Anomalies in Oculoauriculo-Vertebral Dysplasia (Goldenhar-Gorlin Syndrome). Childs Brain, 11, 285-297.

https://doi.org/10.1159/000120189

[9] Kumar, R., Balani, B., Patwari, A.K., Anand, V.K. and Ahuja, B. (2000) Goldenhar Syndrome with Rare Associations. Indian Journal of Pediatrics, 67, 231-233.

https://doi.org/10.1007/BF02723669 